\section{Carbon cost will not stop oil-sands work}

Wendy Palen and colleagues propose a moratorium on new oil-sands projects until regulations are in place to ensure compliance with carbon-emissions commitments (Nature 510, 465-467; 2014).

We question whether such a ban is justified on the basis of the criteria they propose.

Emissions from oil-sands production are generally less than 0.1 tonne of carbon dioxide equivalent per barrel, so production costs would increase by at most US $\$ 6.50$ per barrel if social costs were accounted for as the authors suggest. The social cost of carbon is estimated at about $\$ 65$ per tonne of $\mathrm{CO}_{2}$ equivalent over the lifespan of an oilsands project (see go.nature. com/9ztmyu).

However, many projects would remain viable despite this production-cost increase, in part because it would be offset for developers by tax and royalty deductions. The energy company Suncor, for example, estimates that a similar carbon policy would decrease its return on investment on a new mine by just $0.4 \%$.

A moratorium is neither sufficient nor necessary for Canada to meet its greenhousegas commitments, or to achieve global carbon stabilization at 450 parts per million (see also N. C. Swart and A. J. Weaver Nature Clim. Change 2, 134-136; 2012).

To meet its target, Canada would probably need to set a carbon price that exceeds the social cost of carbon estimates - say, more than $\$ 100$ per tonne (see go.nature. com/dswyma) - and apply it nationally to all sources of emissions. Even then, oil-sands production could continue to grow.

Andrew Leach, Branko

Boskovic University of Alberta, Canada. aleach@ualberta.ca

A.L. declares competing

financial interests: see go.nature. com/4zleed for details.

\section{Put brain project back on course}

As an ambitious initiative of the European Commission, the Human Brain Project (HBP) must unite basic neuroscience research with information and communication technology (see www.humanbrainproject.eu).

However, many neuroscientists are concerned that it has failed to do so (see http://neurofuture.eu) We believe that it is not too late to put the HBP on course and restore confidence by swift and decisive action.

In our opinion, to let the HBP plough ahead without taking into account widespread views within the European neuroscience community would be akin to giving the lead on climate studies to the critics of global warming. Cooperative and effective large-scale research cannot be decreed: it has to emerge from inclusive discussion and respect for scientific argument.

This will require the European Commission to implement significant changes. For example, the HBP charter needs to be amended to make its governance much more democratic: the direction of a project on this scale must reflect a maximally consensual scientific process. We also suggest that a neuroscience council should be created to formulate a strategy for Europe that is inclusive and scientifically driven, and which would help to drive partnering grants and international collaboration.

We stand committed to working with the European Commission and the HBP, but inclusivity and good governance are essential to meet the huge challenges of understanding the human brain.

Zachary F. Mainen

Champalimaud Neuroscience
Programme, Lisbon, Portugal. zmainen@neuro.fchampalimaud. org

Alexandre Pouget University Medical Center, University of Geneva, Switzerland.

\section{Review risks before eradicating toads}

Jonathan Kolby and colleagues call for swift eradication of the invasive Asian common toad Duttaphrynus melanostictus from Madagascar (Nature 509, 563; 2014). We caution against disproportionate countermeasures that are not founded on proper data and assessment. These could have detrimental effects on local ecosystems that are comparable to the threat posed by the toads themselves.

Draining potential breeding ponds, for example (see Nature http://doi.org/ts3; 2014), could have an impact on local fauna or even on entire ecosystems. This approach would probably fail anyway because larvae of D. melanostictus can survive in streams, puddles and brackish waters. Also, efforts by amateur conservationists and locals to destroy toad spawn and larvae could jeopardize native frog species if people do not identify tadpoles or juveniles correctly (see, for instance, R. Somaweera et al. Biol. Conserv. 143, 1477-1484; 2010).

We consider the parallels drawn by Kolby and colleagues between $D$. melanostictus and the invasive cane toad (Rhinella marina) to be inappropriate. Invasion potential and the effects of alien species are hard to predict without sufficient data. To confirm a genuine biological invasion, information first needs to be collected on the toads' range extension and the impact on local flora and fauna.

Before implementing countermeasures, any negative effects should be evaluated. This calls for rapid assessment of the practical difficulties, risks and prospects of success. Sven Mecke ${ }^{\star}$ Philipps-Universität Marburg, Germany. meckes@staff.uni-marburg.de ${ }^{\star}$ On behalf of 12 correspondents (see go.nature.com/wj2aju for full list).

\section{University managers misled by metrics}

University administrators wishing to arrive at rapid decisions in evaluating staff performance may ignore metrics that seem too sophisticated (Nature 510, 444; 2014, and see J. Adams Nature 510, 470-471; 2014). At King's College London, for example, appallingly blunt metrics are being wielded to determine who should be made redundant.

Some faculty members there are being appraised on grant income or hours of contact teaching, but not both, and without regard to indicators such as publication record, teaching quality or editorial-board membership (see go.nature.com/ bhbyjs). These metrics are having a disproportionate effect on staff with both research and teaching commitments - ironically, the university's stated ideal.

Total grant income is in any case a questionable proxy for research quality, and cannot be used to compare the performance of researchers who have different outgoings and funding sources. Examples include basic and medical researchers, or those who work on model organisms that vary markedly in expense. Their grant sizes are unrelated to the quality of their research.

Such misleading measures cannot inform the shrewd decision-making that is essential for tightly funded higher-education management. Thomas Butts King's College London, UK. thomas.butts@kcl.ac.uk The author declares competing financial interests: see go.nature. com/u9y5ti for details. 